\title{
DESIGN E ACESSIBILIDADE EM INTERFACES: ENSAIO DE INTERAÇÃO EM UM SITE BILÍNGUE (LIBRAS-PORTUGUÊS)
}

\author{
DESIGN AND ACCESSIBILITY IN INTERFACES: INTERACTION TEST ON \\ A BILINGUAL SITE \\ Laíse Miolo de Moraes ${ }^{1}$, M.Sc. \\ Berenice Santos Gonçalves ${ }^{2}$, D.Sc. \\ Daniel Scandolara ${ }^{3}$, Esp.
}

(1) Instituto Federal de Santa Catarina e-mail: laisemores@gmail.com

(2) Universidade Federal de Santa Catarina e-mail: bereni.gon@gmail.com

(3) Instituto Federal de Santa Catarina

e-mail: $\underline{\text { daniel.scandolara@gmail.com }}$

Design de Interfaces, Acessibilidade, Design de Interação.

\begin{abstract}
A cada ano aumentam as preocupações com a acessibilidade em interfaces digitais, seja para possibilitar o acesso do maior número de pessoas, como para incluir sujeitos com alguma desabilidade. No entanto, no caso da acessibilidade para pessoas surdas, a web garante apenas parte dos seus desafios de comunicação. Embora existam algumas diretrizes, essas quase sempre se traduzem para a língua oral e escrita de cada país, não contemplando o aspecto fundamental da cultura dessas pessoas, a língua de sinais. Assim, o objetivo deste trabalho é investigar o processo de interação e usabilidade do usuário surdo com um site bilíngue (Libras/Português), do Campus Palhoça Bilíngue, por meio de um ensaio de interação. É uma pesquisa exploratória e descritiva, sua abordagem é qualitativa e os procedimentos técnicos serão bibliográficos, que abordam da cultura surda e o uso das tecnologias, do design de interação e acessibilidade, bem como recomendações para interfaces acessíveis para surdos. $\mathrm{O}$ ensaio de interação foi conduzido com a participação de 3 usuários surdos, com base na análise de tarefas, questionário e entrevista com os voluntários. Os resultados apontam contribuições com as recomendações para interfaces bilíngues, para o redesign da interface e emerge questões para estudos futuros, quanto ao processo cognitivo de leitura da informação do surdo.
\end{abstract}

Design of Interfaces, Accessibility, Design of Interaction.

Realização:
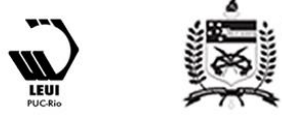

UNIVERSIDADE FEDERAL

DE SANTA CATARINA
INSTITUTO FEDERAL

Santa Catarina

Câmpus Palhoça Bilíngue 
$16^{\circ}$ Ergodesign - Congresso Internacional de Ergonomia e Usabilidade de Interfaces Humano Tecnológica: Produto, Informações Ambientes Construídos e Transporte

$16^{\circ}$ USIHC - Congresso Internacional de Ergonomia e Usabilidade de Interfaces Humano Computador

CINAHPA | 2017 - Congresso Internacional de Ambientes Hipermídia para Aprendizagem.

Concerns about accessibility on digital interfaces increase every year, whether to enable access by as many people as possible, or to include subjects with some disability. However, in the case of accessibility for deaf people, the web guarantees only part of its communication challenges. Although there are some guidelines, these almost always translate into the oral and written language of each country, not contemplating the fundamental aspect of the culture of these people, sign language. Thus, the objective of this work is to investigate the process of interaction and usability of the deaf user with a bilingual site (Libras / Português), of the Palhoça Bilingual Campus, through an interaction test. It is an exploratory and descriptive research, its approach is qualitative and technical procedures will be bibliographical, dealing with deaf culture and the use of technologies, interaction design and accessibility, as well as recommendations for accessible interfaces for the deaf. The interaction test was conducted with the participation of 3 deaf users, based on task analysis, questionnaire and interview with the volunteers. The results point to contributions with the recommendations for bilingual interfaces, to the redesign of the interface and questions emerge for future studies regarding the cognitive process of reading the information of the deaf.

\section{Introdução}

Um dos maiores problemas de acessibilidade em interfaces para o usuário surdo, é a falta do uso da Língua de Sinais, sua primeira língua. Isso acontece muitas vezes, pelo desconhecimento dessas especificidades em relação à cultura surda e também por falta de orientações consistentes para adaptações ou projetos de Interfaces para esse público.

Atualmente as pesquisas sobre acessibilidade encontram-se em constante desenvolvimento, contando com diversos grupos de pesquisas, a saber o Grupo de Trabalho de Acessibilidade na Web do W3C ${ }^{1}$, que foi criado para discutir e planejar ações em favor da acessibilidade na web. Segundo um estudo realizado pelo W3C.br/NIC.br, somente $2 \%$ das páginas web governamentais são acessíveis (W3CGT, 2016). Em Santa Catarina, grupos de pesquisa do CNPq: "Núcleo de Acessibilidade Digital e Tecnologias Assistivas UFSC" e o grupo "Desenvolvimento de Objetos de Ensino e Aprendizagem Bilíngues - IFSC", convergem esforços para a pesquisa relacionada à acessibilidade em ambientes virtuais de aprendizagem, interfaces web, objetos de aprendizagem, glossários e ferramentas web colaborativas.

\footnotetext{
${ }^{1}$ http://www.w3c.br/Home/WebHome
}

Os desafios desses projetos são hercúleos, devido à complexidade do registro da Língua de Sinais e da cultura surda. A língua do surdo é considerada na modalidade "visual-espacial", ou seja, é executada pelas mãos no espaço e percebida de maneira visual, e por isso, requer ser reproduzida em vídeos, ilustrações ou animações (QUADROS, 2008). Sua versão escrita, o "Sign Writting" ainda é pouco difundida e tem poucos usuários (PIVETTA et. al, 2012). Para Flor, Vanzin e Ulbricht (2013), o bilinguismo, que hoje aceito e adotado na constituição de muitos países é fruto de um processo histórico que deve ser estendido à acessibilidade na web, evitando assim que os problemas da educação dos surdos sejam transferidos à web.

Diante dessa problemática, encontra-se uma lacuna de pesquisa sobre Interfaces Acessíveis, no que tange às adaptações, o design e avaliações necessárias nesse processo. Portanto, o objetivo deste trabalho é avaliar a qualidade do processo de interação e usabilidade do site do IFSC - Câmpus Palhoça Bilíngue, tendo em vista o perfil do público surdo, por meio de um ensaio de Interação. E ainda, pretende-se avaliar o nível de satisfação do surdo em relação a interface bilíngue do site em questão.

Assim, este trabalho estrutura-se a partir de uma busca de referências bibliográficas que contextualizam a cultura surda e o uso das 
$16^{\circ}$ Ergodesign - Congresso Internacional de Ergonomia e Usabilidad de Interfaces Humano Tecnológica: Produto, Informações Ambientes Construídos e Transporte

$16^{\circ}$ USIHC - Congresso Internacional de Ergonomia e Usabilidade de Interfaces Humano Computador

CINAHPA | 2017 - Congresso Internacional de Ambientes Hipermídia para Aprendizagem.

tecnologias, os conceitos de acessibilidade e recomendações existentes para interfaces bilíngues. Já nos procedimentos metodológicos se desenha o estudo, como um ensaio de interação com o público surdo a respeito do site bilíngue do IFSC Palhoça.

\section{A cultura surda e o uso das tecnologias}

A cultura se expressa a partir da linguagem, dos juízos de valor, da arte, das motivações, etc., gerando a ordem do grupo, com seus códigos próprios, suas formas de organização, de solidariedade, etc. Os elementos culturais constituem-se na mediação simbólica que torna possível a vida em comum e as culturas são recriadas em função de cada grupo que nelas se inserem. Os surdos são um grupo minoritário que está lutando para que sua cultura seja incluída, no contexto social, como legítima (SÁ, 2006).

Durante muitos anos as línguas de sinais foram proibidas aos surdos por serem consideradas um meio de comunicação inferior, inconveniente e destituída de rigor científico. A partir de Stokoe (1960), passou-se a ver a língua de sinais como realmente uma língua e não apenas como mero gesto. Segundo Gesser (2009), as Línguas de Sinais possuem todas as características das línguas orais, como a polissemia, possibilidade de utilização de metáforas, piadas, jogos de linguagem, etc. As línguas de sinais são basicamente diferentes das línguas orais devido à sua modalidade visual-espacial, que faz com que sejam percebidas através da visão e produzidas através das mãos e das expressões faciais e corporais. Já as línguas orais, como o Português caracterizam-se de maneira oral-auditiva.

O bilinguismo refere-se a aquisição e utilização de duas línguas, no caso da pessoa surda, a Língua de Sinais é a língua materna e a segunda língua é aquela utilizada em seu país, na modalidade escrita. Nesse sentido, a proposta bilíngue entende o sujeito surdo como participante de duas realidades, vivendo ao mesmo tempo a cultura da língua materna, na qual tem sua visão de mundo construída, e a cultura de uma segunda língua, a utilizada no cotidiano da comunidade a que pertence.

Assim, a filosofia bilíngue empodera o sujeito surdo, que não busca a adequação à realidade ouvinte, usuária da língua oral, mas assume sua condição de surdez como parte de suas características e identidade. A cultura surda trata de ver o surdo no aspecto da diferença e não da deficiência, como supõe a área médica (SANTANA, 2007). Dessa maneira, os surdos formam uma comunidade, com cultura e língua próprias (PEREIRA, 2009) (GOLDFELD, 2002).

No entanto, por muito tempo as comunidades de surdos estiveram fechadas e isoladas, por conta de barreiras físicas de distância ou de acesso aos tradicionais meios de comunicação e tecnologias utilizadas pela maioria ouvinte. Com o acesso às Tecnologias de Informação e Comunicação (TIC's), que abrangem uma rede de áreas distintas, com o objetivo de promover a comunicação e a troca de informação, a população com perda auditiva encontrou uma nova forma de comunicação (MORAES, L. M.; BUBNIAK, F. P.; VELLOSO, B. P.; KAMINSKI, D., 2014).

Logo, com o uso das mídias digitais, câmeras fotográficas e vídeos, bate-papos com webcams e aplicativos de mensagens de texto, a comunicação entre usuários da língua de sinais ampliaram-se consideravelmente, assim como a difusão e reconhecimento dessa língua pela maioria usuário das línguas faladas.

Atualmente existem algumas interfaces em Língua de Sinais, por vezes adaptadas ao público surdo ou projetadas especialmente para esses usuários, a saber: a TV INES ${ }^{2}$, o aplicativo brasileiro de

\footnotetext{
${ }^{2}$ www.tvines.com.br
}

Realização:

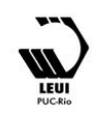


$16^{\circ}$ Ergodesign - Congresso Internacional de Ergonomia e Usabilidade de Interfaces Humano Tecnológica: Produto, Informações Ambientes Construídos e Transporte

$16^{\circ}$ USIHC - Congresso Internacional de Ergonomia e Usabilidade de Interfaces Humano Computador

CINAHPA | 2017 - Congresso Internacional de Ambientes Hipermídia para Aprendizagem.

tradução por avatar - Pro Deaf ${ }^{3}$, o site acadêmico do curso Letras Libras da Universidade Federal de Santa Catarina ${ }^{4}$ e o site do IFSC Palhoça Bilíngue ${ }^{5}$. E ainda em fase de desenvolvimento, o grupo de pesquisa $^{6}$ "Desenvolvimento de Objetos de Aprendizagem Bilíngue" vinculado ao CNPq, está trabalhando na construção de uma ferramenta web colaborativa vinculada a mídias sociais de um glossário em Libras.

No entanto, a maioria dessas interfaces têm sido desenvolvidas de maneira empírica, muitas vezes sem o conhecimento ou participação efetiva de um usuário surdo. O que implica em problemas de barreiras de acessibilidade e a nível de experiência e baixo engajamento dos sujeitos aos quais se destinam os projetos.

\section{Design de Interação e Usabilidade}

As novas tecnologias da informação e comunicação, assim como, uma maior preocupação com a usabilidade nas interfaces estão facilitando a vida dos surdos e atraindo cada vez mais usuários. No entanto, esse contexto linguístico é uma demanda relativamente nova para a área de Interação Humano Computador (IHC), campo de estudo interdisciplinar que procura entender como e porque as pessoas utilizam a tecnologia da informação. O objetivo é o projeto e desenvolvimento de sistemas com o propósito de melhorar a eficácia e proporcionar satisfação ao usuário (MORAES, A. M; ROSA, G. S., 2012).

$\mathrm{Na}$ área de IHC são adotadas pesquisas e recomendações de usabilidade com o intuito de facilitar o acesso e a navegação dentro do site ou sistema. Embora essa prática mostre a preocupação com a qualidade da experiência interativa que o usuário terá, muitas vezes, não é contextualizada

\footnotetext{
${ }^{3}$ http://prodeaf.net/

${ }^{4}$ http://libras.ufsc.br/

${ }^{5}$ http://palhoca.ifsc.edu.br/

${ }^{6}$ http://dgp.cnpq.br/dgp/faces/consulta/consulta_para metrizada.jsf
}

de forma correta ou não se aplica à casos específicos. Em função disso, muitos profissionais têm realizado suas próprias pesquisas, com enfoque no sistema a ser desenvolvido ou já implementado.

No desenvolvimento de interfaces, deve-se priorizar os objetivos do produto e as necessidades do usuário. Para tanto, técnicas de projeto e avaliação da usabilidade são adotadas com o intuito de promover interações mais fáceis e agradáveis. Deve-se, portanto, criar mecanismos para minimizar sobrecargas cognitivas e aliar os aspectos de design gráfico e de estética à usabilidade (SANTA ROSA; MORAES, 2008).

Para Preece, Rogers e Sharp (2013, p. 08), projetar uma interação "significa criar experiências que melhorem e entendam a maneira como as pessoas trabalham, se comunicam e interagem. (...) Nesse sentido, consiste em encontrar maneiras de fornecer suporte às pessoas". Deste modo, aumenta a complexidade do desenvolvimento de interfaces, sendo necessário compreender com maior profundidade o tratamento das informações visuais e o conhecimento do público para o qual se projetará.

Nesse sentido, para essas autoras, o processo de entender as necessidades do usuário é muito importante e dentre as principais preocupações estão as metas de usabilidade e as metas decorrentes da experiência do usuário:

Tradicionalmente, as metas de usabilidade se preocupam com um conjunto de critérios de usabilidade específicos, por exemplo, eficiência; enquanto, mais recentemente, as metas da experiência de usuário têm se preocupado em explicar a natureza da esperiência de usuário, por exemplo, se é esteticamente agradável. (PREECE, ROGERS e SHARP, 2013, p. 17)

\section{Acessibilidade}

Segundo os dados da Organização Mundial da
Realização:

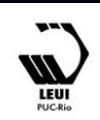


$16^{\circ}$ Ergodesign - Congresso Internacional de Ergonomia e Usabilidade de Interfaces Humano Tecnológica: Produto, Informações Ambientes Construídos e Transporte

Saúde (2012), estima-se que mais de um bilhão de pessoas no mundo vivem com algum tipo de desabilidade. Sendo que estes indivíduos possuem menos oportunidades de acesso ao mercado de trabalho como também no acesso a informação. E, segundo censo realizado em 2010 pelo Instituto Brasileiro de Geografia e Estatística-IBGE, cerca de 9,7 milhões de brasileiros possuem deficiência auditiva, deste total cerca de 2 milhões possuem a deficiência auditiva severa (ADAP, 2013).

Nesse contexto, segundo o W3.org a acessibilidade dos recursos web é uma premissa fundamental para a inclusão na atual sociedade:

\begin{abstract}
A Web é fundamentalmente concebida para trabalhar para todas as pessoas, independentemente do seu hardware, software, língua, cultura, localização, ou a capacidade física ou mental. Quando o Web atende a esse objetivo, é acessível a pessoas com uma gama diversificada de audição, movimento, visão e capacidade cognitiva. Assim, o impacto da deficiência é alterada radicalmente na Web porque o Web remove barreiras à comunicação e interação que muitas pessoas enfrentam no mundo físico. (W3.ORG, 2016).
\end{abstract}

A Web Accessibility Initiative (WAI) do World Wide Web Consortium (W3C), é uma iniciativa que tem como intuito apoiar o desenvolvimento de uma Web acessível, estudando e propondo diretrizes, critérios, técnicas e ferramentas auxiliares para eliminar ou minimizar as barreiras de acessibilidade nos sites. As diretrizes vigentes são as apresentadas no Web Content Accessibility Guidelines 2.0 (WCAG 2.0, 2014).

Em 2016, a W3C Brasil publicou o segundo fascículo da Cartilha de Acessibilidade na Web, que aborda temas relacionados aos benefícios, legislação e diretrizes de acessibilidade na Web. No entanto, em relação a acessibilidade da pessoa surda ou com deficiência auditiva, a única diretriz geral apontada é a necessidade do acesso de informações em áudio e vídeo com legendas, transcrições e traduções em LIBRAS (Língua Brasileira de Sinais) (W3C.ORG, 2016).

Em complemento, um estudo de Flor, Vanzin e Ulbricht (2013) a respeito das Recomendações da WCAG 2.0 (2008) e a acessibilidade de surdos em conteúdos da Web, mostra que grande parte das diretrizes não estão de acordo com foco na cultura surda e no acesso dos surdos aos conteúdos na sua primeira língua, a Libras. Ao contrário, as recomendações são focadas em tradução em formato de texto para os conteúdos sonoros:
A WCAG 2.0 contempla apenas parte dos desafios da comunicação de surdos na web. Embora estabeleça diretrizes para que os conteúdos sonoros possam ser disponibilizados por meio de legendas e alternativas de mídia, essas recomendações quase sempre se traduzem para a língua oral de cada país, e apenas um, dos seis critérios de sucesso relacionados à surdez, refere-se à língua de sinais. (FLOR, VANZIN, ULBRICHT, 2013)

Assim, foi necessário aprofundar o contexto de pesquisa em acessibilidade web, pesquisando-se por meio de revisão de literatura outras recomendações e diretrizes de interfaces para surdos e apresenta-se os resultados encontrados no item seguinte.

\subsection{Recomendações para Interfaces Acessíveis}

Visto que as normas estabelecidas pela WCAG 2.0 no ambiente da web não vão ao encontro da cultura surda, pois distancia o surdo das línguas de sinais, foi necessário encontrar outras referências e orientações para interfaces para surdos.

Em Pivetta et. al (2012), no estudo Contribuições para o design de interface de um Ambiente Virtual de Ensino Aprendizagem acessível a surdos, delineou-se algumas recomendações para:

Design da informação visual e estruturação das
Realização:

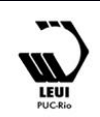


$16^{\circ}$ Ergodesign - Congresso Internacional de Ergonomia e Usabilidade de Interfaces Humano Tecnológica: Produto, Informações Ambientes Construídos e Transporte

interfaces: valorizar o componente visual: evitar textos longos; evitar sistemas de navegação exclusivamente baseados em texto; cuidados com o uso de cores, implementar mecanismos de controle de velocidade das legendas;

Estudar formas de integrar ferramentas das redes sociais nestes ambientes; sensibilizar, apoiar e qualificar as equipes de apoio e desenvolvimentos dos AVEAs para a realidade da surdez.

Em complemento, Flor e Vanzin (2015) através do estudo de Ambientes Virtuais de ensino e aprendizagem e Comunidade de prática acessíveis para surdos sob a ótica da Teoria da Cognição Situada, partem de uma revisão sistemática em que foram selecionadas sete publicações, que apresentavam características e recomendações:

Uso da Língua de Sinais: apresentar as informações de maneira bilíngue, tanto na língua oral, quanto na língua de sinais. Os vídeos em língua de sinais devem ser apresentados imediatamente ao lado da informação de texto. A acessibilidade dos vídeos pode ser melhorada com a inserção de legendas para o conteúdo falado e para descrever outras informações de som. Tradutores automáticos ainda precisam evoluir para ser aceitos plenamente pelos surdos.

Uso de recursos visuais: importância de que os elementos multimídias sejam reproduzidos conforme a escolha do usuário. A reprodução do vídeo em língua de sinais, juntamente ao texto e às imagens, ao mesmo tempo, pode diminuir a compreensão e o reconhecimento das palavras entre os estudantes surdos, devido ao aumento da sobrecarga cognitiva gerada. Explorar a visualidade, possuir uma interface atraente, de modo a complementar ou substituir as informações de texto e sons por recursos visuais. Animações são um recurso extremamente importante para a explicação de conceitos e para a demonstração do funcionamento de certas ferramentas.
Uso de escrita e legendas em ambientes para a aprendizagem: uso de legendas para qualquer conteúdo que contenha áudio, tais como vídeos, animações ou podcasts. A legenda deve ser equivalente ao texto falado e deve conter outras informações sonoras como, por exemplo, o toque de um telefone e ser apresentada na parte inferior do vídeo.

Uso de ferramentas de apoio linguístico: criação de glossários, que ajudariam também os intérpretes a entrar em contato com termos técnicos específicos de cada área. Possibilitar realizar anotações diretamente no vídeo e em tempo real; possibilitar a tradução para que cada membro possa utilizar as ferramentas síncronas ou assíncronas em sua língua.

\section{Procedimentos Metodológicos}

O presente estudo caracteriza-se como pesquisa científica teórica-empírica, que busca descobrir novos conhecimentos sobre o processo de interação e usabilidade de um site bilíngue.

Quanto aos objetivos a pesquisa é do tipo exploratória e descritiva, uma vez que será explorada a realidade empiricamente em busca de maior conhecimento para posterior descrição. Segundo Gill (2008) "explora-se a realidade em busca de conhecimento" e "descreve-se o objeto do estudo, com a máxima exatidão possível os fatos e fenômenos". A abordagem é qualitativa e conta com uma pesquisa bibliográfica, uma vez que se buscou em livros, artigos, bancos de teses e dissertações, etc. a base conceitual para intermediar a discussão dos resultados.

Desse modo, foi realizado um ensaio de interação a partir do uso do site do Instituto Federal de Educação, Ciência e Tecnologia de Santa Catarina - IFSC, Campus Palhoça Bilíngue (Libras/Português), com 3 usuários surdos ${ }^{7}$.

${ }^{7}$ Segundo Krug (2010), pelo menos 1 usuário para uma
Realização:

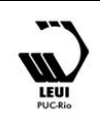


$16^{\circ}$ Ergodesign - Congresso Internacional de Ergonomia e Usabilidade de Interfaces Humano Tecnológica: Produto, Informações Ambientes Construídos e Transporte

$16^{\circ}$ USIHC - Congresso Internacional de Ergonomia e Usabilidade de Interfaces Humano Computador

\section{Apresentação}

No ano de 2012, foi projetado e implementado o site bilíngue (Libras-Português) do Instituto Federal de Santa Catarina - Campus Palhoça, que atende a alunos, professores, servidores e público em geral interessado no Campus. O projeto contou com uma equipe interdisciplinar, um designer, dois programadores, um assistente em filmagem e edição, intérpretes da língua de sinais e também professores surdos.

Essa interface foi desenvolvida de modo qualitativo, a partir da experiência da equipe e das observações e opiniões dos surdos. O layout e a programação do site foi baseado no template e software de programação utilizado na rede de Institutos Federais, o Joomla, com adaptações necessárias para a inclusão gifs animados e de vídeos na língua de sinais.

Em 2014 foi feito um estudo de inspeção, a partir as Heurísticas de Nielsen (1995) e das

Recomendações de Usabilidade de Jordan (1998). Os resultados apontam uma contribuição na área de Design de interface e tecnologias acessíveis, indicando recomendações para interfaces bilíngues (MORAES, L. M.; BUBNIAK, F. P.; VELLOSO, B. P.; KAMINSKI, D., 2014).

A figura 1 mostra a página inicial do site bilíngue. No menu superior constam todos os botões com a sinalização em Libras da palavra em Português. O submenu fica à esquerda, com um gif animado de tradução, que se modifica conforme o cursor do mouse passa na lista de links (palavras em português). À direita ficam os ícones tiipo "banners" de acesso rápido à: biblioteca, inscrição para cursos, moodle e outras informações esporádicas. No centro da interface está o conteúdo principal que se acesso através dos menus. $\mathrm{Na}$

avaliação de interação já é suficiente para encontrar tantos problemas de usabilidade quanto usando mais participantes no teste. página inicial, o centro da interface é composto por uma página de notícias, atualizadas e em formato de paginação, do tipo "linha do tempo".

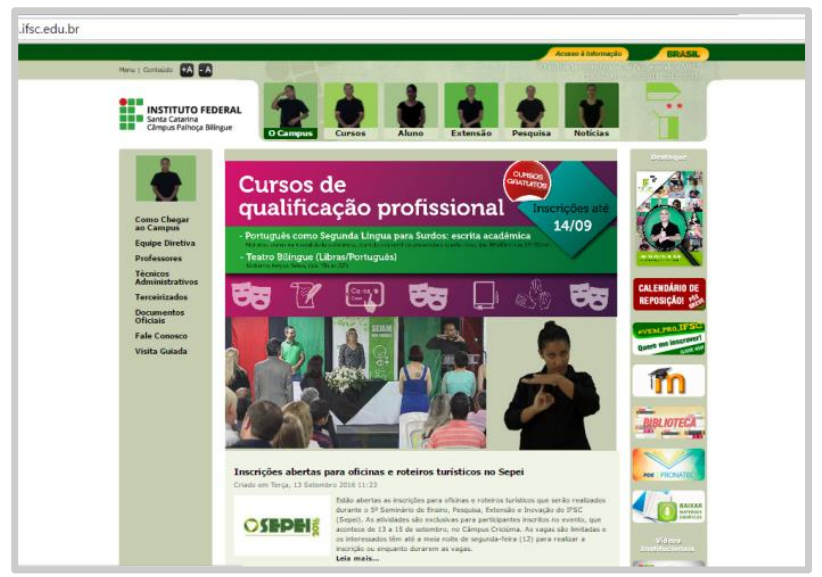

Figura 1: Página Inicial do site do IFSC Palhoça Bilíngue. Fonte: IFSC Palhoça Bilíngue, 2016.

\subsection{Ensaio de Interação}

O Ensaio de Interação foi feito com 3 participantes $\operatorname{surdos}^{8}$, alunos do ensino superior do IFSC Palhoça em um laboratório de informática do Campus. A pesquisa contou com a tradução simultânea do Português para Língua de Sinais ${ }^{9}$, gravação da tela dos usuários com o software Camtasia e filmagem em vídeo das entrevistas.

Para a seleção desses 3 participantes foi realizado um questionário inicial para avaliar o perfil dos voluntários. Foram feitas perguntas sobre: o uso prévio do site bilíngue, o domínio do portuguê e o conhecimento de outras interfaces bilíngues, conforme o Quadro 1.

\footnotetext{
${ }^{8}$ Os participantes foram voluntários e assinaram um Termo de Consentimento e Livre Esclarecimento, conforme a Resolução no 466 e suas complementares de 12 de dezembro de 2012 do Conselho Nacional de Saúde.

${ }^{9}$ A tradução foi feita pelo Professor Esp. Daniel Scandolara, certificado no Pró-Libras (2015).
}

Realização:

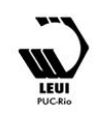



USIHC de Interfaces Humano Tecnológica: Produto, Informações Ambientes Construídos e Transporte

$16^{\circ}$ USIHC - Congresso Internacional de Ergonomia e Usabilidade de Interfaces Humano Computador

\begin{tabular}{|c|l|l|l|}
\hline Participante & $\begin{array}{l}\text { Conheci- } \\
\text { mento do } \\
\text { Site do IFSC }\end{array}$ & $\begin{array}{l}\text { Conheci- } \\
\text { mento do } \\
\text { Português }\end{array}$ & $\begin{array}{l}\text { Conheci- } \\
\text { mento de } \\
\text { Outras } \\
\text { interfaces } \\
\text { bilíngues }\end{array}$ \\
\hline P1 & $\begin{array}{l}\text { Conhece, } \\
\text { não usuário }\end{array}$ & $\begin{array}{l}\text { Razoável, Lê } \\
\text { pouco. }\end{array}$ & $\begin{array}{l}\text { Não } \\
\text { conhece. }\end{array}$ \\
\hline P2 & $\begin{array}{l}\text { Conhece, } \\
\text { não usuário }\end{array}$ & $\begin{array}{l}\text { Razoável, Lêe } \\
\text { bem, } \\
\text { escreve } \\
\text { pouco. }\end{array}$ & $\begin{array}{l}\text { Conhece. } \\
\text { Utiliza o site } \\
\text { do INES e o } \\
\text { dicionário } \\
\text { Libras } \\
\text { Português. }\end{array}$ \\
\hline P3 & $\begin{array}{l}\text { Conhece, é } \\
\text { usuário }\end{array}$ & $\begin{array}{l}\text { Compreen- } \\
\text { de mal. } \\
\text { Acha difícil. }\end{array}$ & $\begin{array}{l}\text { Conhece o } \\
\text { Letras Libras } \\
\text { da UFSC. }\end{array}$ \\
\hline
\end{tabular}

Quadro 1: Resultados da entrevista inicial dos participantes. Fonte: Elaborado pelos autores.

Para a Interação com o site, foi criado um cenário de uso. Pediu-se que eles realizassem 3 tarefas, que consistiam em buscas e situações que apareceram durante o uso: encontrar o e-mail de um professor, acessar informações sobre um curso técnico e ler uma notícia específica passada. Estas buscas estavam relacionadas ao uso de menus principais e submenus (buscar curso), ao reconhecimento e lembrança de imagens ou gifs (contato de professor) e uso e entendimento de paginação (na busca por notícias passadas). A interação foi observada pelos pesquisadores, o tempo foi contado e os resultados das tarefas estão no quadro 2:

\begin{tabular}{|c|c|c|c|}
\hline $\begin{array}{l}\text { Tempo de } \\
\text { Interação }\end{array}$ & $\begin{array}{l}\text { Tarefa 1: } \\
\text { Encon- } \\
\text { trar contato } \\
\text { de profes- } \\
\text { sor }\end{array}$ & $\begin{array}{l}\text { Tarefa 2: } \\
\text { Encontrar } \\
\text { informa- } \\
\text { ções sobre o } \\
\text { curso } \\
\text { técnico de } \\
\text { Tradução e } \\
\text { Interpreta- } \\
\text { ção }\end{array}$ & $\begin{array}{l}\text { Tarefa 3: } \\
\text { Encontrar } \\
\text { notícia } \\
\text { passada } \\
\text { sobre o } \\
\text { "PAEVS" }\end{array}$ \\
\hline \multicolumn{4}{|c|}{ P1 } \\
\hline $19 \mathrm{~min}$. & $\begin{array}{l}\text { Encontrou } \\
\text { rapida- } \\
\text { mente }\end{array}$ & $\begin{array}{l}\text { Não } \\
\text { encontrou }\end{array}$ & Encontrou \\
\hline \multicolumn{4}{|c|}{ P2 } \\
\hline $11 \mathrm{~min}$. & $\begin{array}{l}\text { Encontrou } \\
\text { rapida- } \\
\text { mente }\end{array}$ & $\begin{array}{l}\text { Não } \\
\text { encontrou }\end{array}$ & Encontrou \\
\hline \multicolumn{4}{|c|}{ P3 } \\
\hline $22 \mathrm{~min}$. & $\begin{array}{l}\text { Não } \\
\text { encontrou }\end{array}$ & $\begin{array}{l}\text { Não } \\
\text { encontrou }\end{array}$ & Encontrou \\
\hline
\end{tabular}

Quadro 2: Resultados das tarefas da interação. Fonte: Desenvolvidos pelos autores.

Logo após a interação, foi feita uma entrevista semi estruturada com algumas perguntas sobre a experiência da interação com cada participante. As perguntas envolviam questões sobre a facilidade de uso da interface, a língua de sinais presente no site, sobre o que se destaca mais no site, e o que faria para melhorar o site para o surdo. As respostas encontram-se no quadro 3.

\begin{tabular}{|l|l|l|l|}
\hline $\begin{array}{l}\text { Facilidade } \\
\text { de uso do } \\
\text { site }\end{array}$ & $\begin{array}{l}\text { Informa- } \\
\text { ções em } \\
\text { português e } \\
\text { libras }\end{array}$ & $\begin{array}{l}\text { O que } \\
\text { chama mais } \\
\text { atenção no } \\
\text { site }\end{array}$ & $\begin{array}{l}\text { O que faria } \\
\text { para } \\
\text { melhorar o } \\
\text { site para o } \\
\text { surdo }\end{array}$ \\
\hline
\end{tabular}




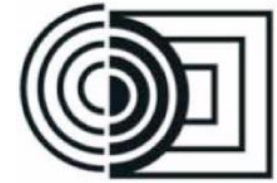

$16^{\circ}$ Ergodesign - Congresso Internacional de Ergonomia e Usabilidade de Interfaces Humano Tecnológica: Produto, Informações Ambientes Construídos e Transporte

$16^{\circ}$ USIHC - Congresso Internacional de Ergonomia e Usabilidade de Interfaces Humano Computador

CINAHPA | 2017 - Congresso Internacional de Ambientes Hipermídia para Aprendizagem.

\begin{tabular}{|c|c|c|c|}
\hline \multicolumn{4}{|c|}{ P1 } \\
\hline Médio & $\begin{array}{l}\text { Bom, é } \\
\text { importante. }\end{array}$ & $\begin{array}{l}\text { O menu da } \\
\text { direita } \\
\text { (banners) }\end{array}$ & $\begin{array}{l}\text { Aumentar a } \\
\text { resolução } \\
\text { do site para } \\
\text { ser } \\
\text { responsivo } \\
\text { na tela } \\
\text { maior. }\end{array}$ \\
\hline \multicolumn{4}{|c|}{$\mathrm{P} 2$} \\
\hline $\begin{array}{l}\text { Médio a } \\
\text { difícil }\end{array}$ & $\begin{array}{l}\text { Bom, mas } \\
\text { leio em } \\
\text { português }\end{array}$ & $\begin{array}{l}\text { Imagens de } \\
\text { anúncio de } \\
\text { novos } \\
\text { cursos na } \\
\text { página de } \\
\text { notícias. }\end{array}$ & $\begin{array}{l}\text { Colocaria o } \\
\text { significado } \\
\text { em Libras de } \\
\text { cada sinal } \\
\text { colocado no } \\
\text { site. }\end{array}$ \\
\hline \multicolumn{4}{|c|}{ P3 } \\
\hline $\begin{array}{l}\text { Médio a } \\
\text { difícil }\end{array}$ & $\begin{array}{l}\text { Muito } \\
\text { importante } \\
\text { ter Libras. }\end{array}$ & $\begin{array}{l}\text { Página } \\
\text { central de } \\
\text { notícias. }\end{array}$ & $\begin{array}{l}\text { Colocaria o } \\
\text { ícone de } \\
\text { "acessível } \\
\text { em libras" } \\
\text { em todos os } \\
\text { vídeos. } \\
\text { Colocaria } \\
\text { libras ao } \\
\text { lado de cada } \\
\text { botão do } \\
\text { menu da } \\
\text { direita. }\end{array}$ \\
\hline
\end{tabular}

Quadro 3: Respostas da entrevista sobre a experiência de Interação. Fonte: Desenvolvido pelos autores.

\subsection{Ensaio de Interação}

A vantagem em se realizar um Ensaio de Interação com observação está na possibilidade do pesquisador observar o comportamento do usuário: hesitações, tentativas e erros, eficácia na realização de algumas tarefas, satisfação ou desgosto durante o uso, bem como ter uma conversa direta com o usuário da interface.

Retomando os objetivos deste trabalho, o principal era avaliar a qualidade do processo de interação e usabilidade do usuário surdo com o site do Câmpus Palhoça Bilíngue e por fim, avaliar a satisfação do surdo com a interface. Desse modo, quanto a satisfação do usuário com a interface com opções na Língua de Sinais, foi positivo, os três participantes avaliaram como muito importante ter a presença da língua de sinais, também a maioria dos voluntários conhecia poucas interfaces com a presença da Libras. Já o processo de interação, avaliou-se como baixo ou negativo, visto que os três participantes sentiram-se "perdidos" em algumas situações de busca no site e não conseguiram realizar todas as tarefas. Também quando perguntado, os três concordaram ser uma interface de difícil manipulação, prejudicando a interação e permanência no site.

Após ensaio de interação e entrevista final, analisou-se as filmagens do monitor e também se reviu as entrevistas. Assim, analisou-se os resultados à luz de quatro questões importantes, que podem ser consideradas na construção de uma interface acessível:

Interação com Menus e Submenus: Observou-se durante a interação, que os três usuários não interagiram prontamente com o menu principal. Apenas um dos usuários fez uma busca pelo menu principal, mas não foi adiante quando encontrou o submenu, parecendo não entender a lista de links por "palavras em português" como "botões".

Interação com a paginação: Quanto a paginação das notícias, os três participantes demonstram entender bem o conceito. O Participantes 3 (P3), declarou que a parte de "notícias" se parece com a rede social "facebook". O que demonstra que o designer deve considerar as mídias com as quais o público tem mais intimidade.

Interação com imagens e ícones: Confirmou-se que as imagens chamam muito a atenção do surdo, pois os três usuários pensaram que as informações pedidas na Tarefa 2 sobre o "curso técnico de 
$16^{\circ}$ Ergodesign - Congresso Internacional de Ergonomia e Usabilidade de Interfaces Humano Tecnológica: Produto, Informações Ambientes Construídos e Transporte

Tradução e Interpretação" estavam nos banners da área de "notícias" ou nos botões "banners" do menu da direita.

Interação com vídeos em Libras: Os gifs em Libras e os vídeos estão presentes em toda interface. Porém, no menu superior quase não foram explorados. Segundo o Participante 2 (P2), os sinais estão sem explicação do significado. Já na parte dos vídeos, nenhum usuário assistiu. Porém se o usuário tivesse assistido um desses vídeos, teria conseguido realizar a Tarefa 2: "encontrar informações sobre o curso de Tradução e Interpretação".

Assim, no caso de um novo projeto do site ou para o design de novas interfaces bilíngues, é necessário: pensar o conceito de "linha do tempo" para conteúdos principais, considerando as referências digitais de uso do público, utilizar a metáfora de "botão" bem definida e se possível com ícones ou imagens, pois o entendimento do surdo é mais rápido nessas situações. E desenvolver traduções rápidas de conceitos necessários para a navegação na interface,

Além disso, com o Ensaio de Interação foi possível corroborar algumas recomendações da revisão bibliográfica e também verificar necessidade urgentes de redesign na interface: os vídeos em língua de sinais devem ser apresentados imediatamente ao lado da informação de texto, pois no site alguns vídeos explicativos não estão ligados aos ícones do menu, e por isso não são acessados pelo usuário. A importância do uso de recursos visuais e substituição de textos, pois muitas vezes as imagens e ícones são acessados mais rapidamente do que as informações em língua de sinais. Verificou-se também a necessidade de criação de glossários para a explicação de ícones do menu.

\section{Considerações Finais}

A partir deste estudo, observou-se que as tecnologias para a acessibilidade facilitam muito a inserção do surdo na comunidade linguística majoritária e atenuam os problemas de comunicação dado por essas diferenças. No entanto, é preciso ampliar as pesquisas com relação à interação e usabilidade com interfaces adaptadas ou projetadas para o público surdo. Pois, como observou-se na literatura, principalmente dos órgãos competentes de acessibilidade como a WCAG 2.0 (2008), as diretrizes não estão de acordo com a cultura surda ao acesso dos conteúdos nas línguas de sinais, sendo que as recomendações continuam focadas em tradução em formato de texto para os conteúdos sonoros.

Nesse contexto, com base em entrevistas e na literatura sobre a cultura surda é possível compreender a necessidade da presença da primeira língua do surdo nas interfaces. No entanto, somente com a pesquisa teórica não se alcança a real percepção do público surdo quando se depara com uma interface acessível. Assim, ressalta-se a importância dos ensaios de interação e testes de usabilidade com o público. Estes ensaios e testes precisam ser bem planejados, muitas vezes requerem a inserção do pesquisador na comunidade surda, para que tenha boa aceitação pelo público. Também precisam de interpretação simultânea ou pré gravada, sendo necessário o conhecimento do intérprete sobre a área do estudo, evitando problemas de compreensão que interfiram nos resultados.

Desse modo, observa-se que para um projeto orientado para o usuário surdo, é preciso a inserção do público durante seu desenvolvimento e constantes testes para a melhoria dos resultados. Além disso, para pesquisas futuras, observou-se a necessidade de compreender de que maneira o surdo entende as informações e hierarquiza dados. Uma vez que as pesquisas já apontam soluções para questões linguísticas e da cultura surda, mas ainda são insuficientes na área da cognição e leitura da informação do surdo, que é essencial para o design da informação de interfaces bilíngues. 
$16^{\circ}$ Ergodesign - Congresso Internacional de Ergonomia e Usabilidade de Interfaces Humano Tecnológica: Produto, Informações Ambientes Construídos e Transporte

$16^{\circ}$ USIHC - Congresso Internacional de Ergonomia e Usabilidade de Interfaces Humano Computador

\section{Referências Bibliográficas}

ADAP. Associação de Deficientes Auditivos, Pais, Amigos e Usuários de Implante Coclear. Deficiência auditiva atinge 9,7 milhões de Brasileiros, 2013. Disponível em: http://www.adap.org.br/site/index.php/artigos/20deficiencia-auditiva-atinge-9-7-milhoes-debrasileiros. Acesso em ago 2016.

FLOR, C.; VANZIN, T. AVEAs e CoPs acessíveis para surdos sob a ótica da Teoria da Cognição Situada. In: Hipermídia e interdisciplinaridade na geração de conhecimento. São Paulo: Pimenta Cultural, 2015.

FLOR, C.; VANZIN, T.; ULBRICHT, V. Recomendações da WCAG 2.0 (2008) e a acessibilidade de surdos em conteúdos da Web. In: Revista Brasileira de Educação Especial. Vol. 19 $n^{\circ} 2$. Marília. Jun/2013.

GESSER, Audrei. Libras? Que língua é essa? Crenças e preconceitos em torno da língua de sinais e da realidade surda. São Paulo: Parábola Editorial, 2009.

GIL, Antonio Carlos. Métodos e Técnicas de Pesquisa Social. 6.ed. São Paulo: Atlas, 2008.

GOLDFELD, M. A criança surda: linguagem e cognição numa perspectiva sociointeracionista. 2. ed. São Paulo: Plexus. 2002.

KRUG, Steve. Não me faça pensar!: Uma abordagem de bom senso à usabilidade na web. 2 . ed. Rio de Janeiro: Alta Books, 2010.

MORAES, A. M.; ROSA, J. G. Avaliação e Projeto no Design de Interfaces. 2Ab, São Paulo, 2012.

ORGANIZAÇÃO MUNDIAL DA SAÚDE. Relatório Mundial sobre a deficiência. 2012.
Disponível em:

http://www.pessoacomdeficiencia.sp.gov.br/usr/sh are/documents/RELATORIO_MUNDIAL_COMP LETO.pdf. Acesso em ago. 2016.

PEREIRA, M. D. C.; VIEIRA, M. D. S.

Bilinguismo e educação de surdos. Revista Intercâmbio, 19, 62-67. São Paulo: LAEL/PUCSP. ISSN 1806-275x, 2009.

PIVETTA, E. M.; SAITO, D. S.; ALMEIDA, A. M. P., ULBRICHT, V. R. Contribuições para o design de interface de um Ambiente Virtual de Ensino Aprendizagem acessível a surdos. In: Revista Brasileira de Design da Informação / Brazilian Journal of Information Design. São Paulo | v. 10 | n. 2 [2013], p. 193 - 206 | ISSN 18085377Blucher. ISSN 2318-6968, DOI

10.5151/designpro-ped-00787

PREECE, Jennifer; ROGERS, Yvonne; SHARP, Helen. Design de Interação: além da interação Homem-Computador. - $3^{\mathrm{a}}$ ed. - Porto Alegre: Bookman, 2013. xiv, 585 p.: il. color.; $25 \mathrm{~cm}$.

QUADROS, R. M. de. (org). Estudos Surdos III. Série pesquisas. Petrópolis, RJ: AraraAzul, 2008.

SÁ, N. L. Cultura, poder e educação de surdos. São Paulo: Paulinas, 2006.

W3C. ACCESSIBILITY. 2016. Disponível em: https://www.w3.org/standards/webdesign/accessibi lity. Acesso em: ago. 2016.

W3CGT. (2016). Acessibilidade. Disponível em: <http://www.w3c.br/GT/Grupo Acessibilidade\#w3c_inicio_conteudo>. Acesso, em ago 2016. 